\title{
Descriptive epidemiology and outcomes of bone sarcomas in adolescent and young adult patients in Japan
}

\author{
Takashi Fukushima ${ }^{1,2}$, Koichi Ogura ${ }^{3,4}$, Toru Akiyama ${ }^{1 *}$ D, Katsushi Takeshita ${ }^{2}$ and Akira Kawai $^{3}$
}

\begin{abstract}
Background: There have been fewer improvements in the clinical outcomes of adolescent and young adult (AYA) patients with cancer than for children and older adults, possibly because fewer studies focus on patients in this age group. The aims of this study were (1) to determine survival rates of bone sarcoma among AYAs in Japan (for comparison with other age groups), and (2) to establish whether belonging to the AYA age group at diagnosis was correlated with poor cancer survival in Japan.

Methods: A total of 3457 patients diagnosed with bone sarcoma (1930 male and 1527 female) were identified from 63,931 records in the Bone and Soft Tissue Tumor (BSTT) registry, a nationwide Japanese database, from 2006 to 2013. The histologic subtypes of bone sarcoma were osteosarcoma, chondrosarcoma, and Ewing sarcoma. The primary endpoints for prognosis were the occurrence of tumor-related death. We compared the epidemiological features of AYAs with other age groups. The cancer survival rates were calculated using the Kaplan-Meier method. Cox proportional hazards models were used to analyze the prognostic factors for cancer survival.
\end{abstract}

Results: The majority of AYA had osteosarcoma 631 (56.2\%), while 198 (17.6\%) had chondrosarcoma. The frequency of bone sarcoma occurrence was highest among AYA patients, who accounted for a marked proportion of patients with each type of sarcoma. With the exception of sarcoma type, AYA patients did not significantly differ from patients in other age groups for any of the investigated clinicopathological parameters. Cancer survival of AYA patients was significantly higher than in the elderly. Univariate and multivariate analyses revealed that AYA status was not a predictor of poor cancer survival. However, older age ( $\geq 65$ years) was a predictor of poor cancer survival in patients with overall bone sarcoma, osteosarcoma, chondrosarcoma.

Conclusion: This epidemiological study is the first to investigate AYA patients with bone sarcoma using the nationwide BSTT Registry. We found that cancer survival of AYA patients was significantly higher than that of the elderly. AYA status was not a predictor of poor cancer survival in Japan.

Keywords: Bone sarcoma, Adolescent and young adult, Cancer survival, Japan, Database

\section{Background}

There have been significant advances in the early detection and treatment of cancer, which have led to improvements in overall survival rates in general patient populations over several decades [1]. However, the clinical outcomes of adolescent and young adult (AYA) patients, defined as those between the ages of 15 to 39, with cancer

\footnotetext{
* Correspondence: toruakiyama827@jichi.ac.jp

${ }^{1}$ Department of Orthopaedic Surgery, Saitama Medical Center, Jichi Medical University, Saitama, Japan

Full list of author information is available at the end of the article
}

have not improved [1-4]. One explanation for this is that, to date, little attention and few resources have been devoted to studying the incidence, biology, and treatment outcomes in AYA patients with cancer [5].

AYA patients with cancer are predominantly afflicted by lymphoma, melanoma, testicular cancer, sarcoma, thyroid cancer, leukemia, and breast cancer [5]. Sarcomas comprise up to $6 \%$ of total malignancies in AYAs and represent one of the most common types of cancer in this population [5]. However, sarcoma is generally a rare disease, and its estimated total crude incidence rate

(c) The Author(s). 2018 Open Access This article is distributed under the terms of the Creative Commons Attribution 4.0 International License (http://creativecommons.org/licenses/by/4.0/), which permits unrestricted use, distribution, and reproduction in any medium, provided you give appropriate credit to the original author(s) and the source, provide a link to the Creative Commons license, and indicate if changes were made. The Creative Commons Public Domain Dedication waiver (http://creativecommons.org/publicdomain/zero/1.0/) applies to the data made available in this article, unless otherwise stated. 
in Europe is 5.6 per 100,000 individuals per year [6]. A few previous studies have investigated the clinical outcomes of AYAs with bone sarcoma using nationwide or large databases with sufficient numbers of patients. However, most previous studies were based on data derived from small numbers of cases, and those with larger sample sizes have only analyzed a few disease-related factors [7-11].

In Japan, no studies on the epidemiology and clinical outcomes of AYA patients with sarcoma compared with patients diagnosed at other ages have been conducted because of the lack of a suitable database. In 2014, the Bone and Soft Tissue Tumor (BSTT) registry-a nationwide organ-specific cancer registry for bone and soft tissue tumors in Japan-became available for the purposes of clinical research, enabling a large-scale nationwide epidemiological investigation of AYA patients with sarcoma.

The aims of the present study were: 1) to determine survival rates of bone sarcoma among AYAs in Japan (for comparison with other age groups), and 2) to establish whether belonging to the AYA age group at diagnosis was correlated with poor cancer survival in Japan.

\section{Methods}

\section{Data source}

The BSTT Registry is a nationwide patient data collection system for organ-specific bone and soft tissue tumors that was launched in the 1950 s by the Japanese Orthopaedic Association (JOA). All JOA-certified hospitals of musculoskeletal oncology (89 facilities) are required to participate in the registry; hence, almost all musculoskeletal malignant tumor cases treated by Japanese orthopedic surgeons are registered.

Detailed data of patients with primary bone and soft tissue tumors (both benign and malignant) and metastatic bone tumors treated at the participating hospitals are collected annually. The BSTT registry survey of patients diagnosed from January 1 to December 31 of the previous year are conducted annually in May. The survey includes basic demographic data of the patient, as well as information on the tumor, surgery, and treatment other than surgery. The next survey is conducted 2,5 , and 10 years after the initial registration at prognosis. The data for patients with bone and soft tissue sarcomas (not for patients with benign and metastatic bone tumors) are collected. It includes information on several outcomes at the time of the latest follow-up.

The BSTT Registry is similar to the Surveillance, Epidemiology, and End Results Program database in the United States; however, it has some additional advantages in that data are provided by the treating physicians themselves, and include histologic findings, treatment modalities, and surgical, functional, and oncologic outcomes.
The Musculoskeletal Tumor Committee of the JOA approved the use of the BSTT Registry for the purposes of clinical research in 2014 [12].

Study approval was obtained from the Institutional Review Board of the JOA.

\section{Data extraction}

The focus of this study was only bone sarcomas recorded in the BSTT Registry for patients diagnosed between 2006 and 2013. Data on 3457 patients with primary bone sarcoma were extracted from the database that encompassed 63,931 patients. Of these, 521, 1123, 982, and 831 were patients aged $\leq 14$ years (children), $15-39$ years (AYAs), $40-64$ years (adults), and $\geq 65$ years (elderly), respectively. The analyzed data included the year of registration; demographic characteristics; tumor size, location, grade, and histological characteristics; TNM and Enneking stages; treatment details (surgical vs. non-surgical); and prognosis at the last follow-up visit (no evidence of disease, alive with disease, dead of disease, or dead of other causes). Patients who were registered less than 2 years from the study enrollment date were excluded. Data on 2651 patients with primary bone sarcoma were extracted from the database. Cases with insufficient data were excluded.

\section{Statistical analyses and study size}

The primary endpoint was the occurrence of tumor-related deaths. The cancer survival time was defined as the period from the date of diagnosis to the tumor-related death. Patients without tumor-related deaths, or patients who died due to other causes, were censored at their last follow-up visit. The cancer survival rates for overall bone sarcoma (all types), osteosarcoma, chondrosarcoma, and Ewing sarcoma were calculated using the Kaplan-Meier method. Cox proportional hazards models were used to analyze the prognostic factors for cancer survival. The variables selected for the analysis were previously reported to be related to cancer survival [13-16]. Control variables for multivariate analysis were indicated by "reference", including AYA, males, low grade, $\leq 8 \mathrm{~cm}$, upper extremity, salvaged and negative. The level of significance was set at $P<0.05$.

IBM SPSS version 19.0 software (IBM SPSS, Armonk, NY, USA) was used for all statistical analyses. The study size was dictated by the total number of patients with bone sarcoma in the BSTT database during the study period.

\section{Results}

The study included 3457 patients with bone sarcoma (1930 male and 1527 female) who were registered in the BSTT database from 2006 to 2013. Table 1 shows characteristics of bone sarcomas in AYAs by age at diagnosis 
Table 1 Characteristics of bone sarcomas in AYAs by age at diagnosis and relevant clinical factor

\begin{tabular}{|c|c|c|c|c|c|c|c|c|c|c|c|}
\hline & \multirow{2}{*}{\multicolumn{2}{|c|}{ Overall }} & \multirow{2}{*}{\multicolumn{2}{|c|}{$\frac{\text { AYA }}{\text { (15-39 years) }}$}} & \multirow{2}{*}{\multicolumn{2}{|c|}{$\frac{\text { Child }}{\text { (-14 years) }}$}} & \multirow{2}{*}{\multicolumn{2}{|c|}{$\frac{\text { Adult }}{\text { (40-64 years) }}$}} & \multirow{2}{*}{\multicolumn{2}{|c|}{$\frac{\text { Elderly }}{\text { (65- years) }}$}} & \multirow[t]{3}{*}{$P$ value } \\
\hline & & & & & & & & & & & \\
\hline & $N$ & $\%$ & $N$ & $\%$ & $\bar{N}$ & $\%$ & $\mathrm{~N}$ & $\%$ & $\mathrm{~N}$ & $\%$ & \\
\hline Total & 3457 & & 1123 & $32.5 \%$ & 521 & $15.1 \%$ & 982 & $28.4 \%$ & 831 & $24.0 \%$ & \\
\hline Histologic subtype & & & & & & & & & & & $<0.001$ \\
\hline Osteosarcoma & 1497 & $43.3 \%$ & 631 & $56.2 \%$ & 405 & $77.7 \%$ & 278 & $28.3 \%$ & 183 & $22.0 \%$ & \\
\hline Chondrosarcoma & 885 & $25.6 \%$ & 198 & $17.6 \%$ & 8 & $1.5 \%$ & 376 & $38.3 \%$ & 303 & $36.5 \%$ & \\
\hline Ewing's sarcoma & 260 & $7.5 \%$ & 139 & $12.4 \%$ & 92 & $17.7 \%$ & 28 & $2.9 \%$ & 1 & $0.1 \%$ & \\
\hline Bone MFH & 205 & $5.9 \%$ & 22 & $2.0 \%$ & 2 & $0.4 \%$ & 82 & $8.4 \%$ & 99 & $11.9 \%$ & \\
\hline Chordoma & 253 & $7.3 \%$ & 16 & $1.4 \%$ & 2 & $0.4 \%$ & 88 & $9.0 \%$ & 147 & $17.7 \%$ & \\
\hline HG sarcoma(others) & 214 & $6.2 \%$ & 52 & $4.6 \%$ & 4 & $0.8 \%$ & 85 & $8.7 \%$ & 73 & $8.8 \%$ & \\
\hline LG sarcoma(others) & 143 & $4.1 \%$ & 65 & $5.8 \%$ & 8 & $1.5 \%$ & 45 & $4.6 \%$ & 25 & $3.0 \%$ & \\
\hline Sex & & & & & & & & & & & 0.028 \\
\hline Male & 1930 & $55.8 \%$ & 656 & $58.4 \%$ & 278 & $53.4 \%$ & 561 & $57.1 \%$ & 435 & $52.3 \%$ & \\
\hline Female & 1527 & $44.2 \%$ & 467 & $41.6 \%$ & 243 & $46.6 \%$ & 421 & $42.9 \%$ & 396 & $47.7 \%$ & \\
\hline Tumor size $(\mathrm{cm})$, mean $[\mathrm{SD}]$ & $9.1[4.9]$ & & $8.8[4.5]$ & & 10.3 & & 8.9[ & & 9.0[ & & $<0.001$ \\
\hline$\leq 8 \mathrm{~cm}$ & 1655 & $47.9 \%$ & 538 & $47.9 \%$ & 193 & $37.0 \%$ & 510 & $51.9 \%$ & 414 & $49.8 \%$ & \\
\hline$>8 \mathrm{~cm}$ and $\leq 16 \mathrm{~cm}$ & 1299 & $37.6 \%$ & 432 & $38.5 \%$ & 246 & $47.2 \%$ & 322 & $32.8 \%$ & 299 & $36.0 \%$ & \\
\hline$>16 \mathrm{~cm}$ & 243 & $7.0 \%$ & 61 & $5.4 \%$ & 50 & $9.6 \%$ & 67 & $6.8 \%$ & 65 & $7.8 \%$ & \\
\hline Unknown & 260 & $7.5 \%$ & 92 & $8.2 \%$ & 32 & $6.1 \%$ & 83 & $8.5 \%$ & 53 & $6.4 \%$ & \\
\hline Tumor location & & & & & & & & & & & $<0.001$ \\
\hline Upper extremity & 349 & $10.1 \%$ & 134 & $11.9 \%$ & 40 & $7.7 \%$ & 105 & $10.7 \%$ & 70 & $8.4 \%$ & \\
\hline Lower extremity & 1689 & $48.9 \%$ & 629 & $56.0 \%$ & 395 & $75.8 \%$ & 399 & $40.6 \%$ & 266 & $32.0 \%$ & \\
\hline Trunk & 1276 & $36.9 \%$ & 303 & $27.0 \%$ & 72 & $13.8 \%$ & 437 & $44.5 \%$ & 464 & $55.8 \%$ & \\
\hline Head and neck & 35 & $1.0 \%$ & 18 & $1.6 \%$ & 2 & $0.4 \%$ & 10 & $1.0 \%$ & 5 & $0.6 \%$ & \\
\hline Multiple disease & 108 & $3.1 \%$ & 39 & $3.5 \%$ & 12 & $2.3 \%$ & 31 & $3.2 \%$ & 26 & $3.1 \%$ & \\
\hline Surgery & 2473 & $71.5 \%$ & 868 & $77.3 \%$ & 430 & $82.5 \%$ & 713 & $72.6 \%$ & 462 & $55.6 \%$ & $<0.001$ \\
\hline Chemotherapy & 1765 & $51.1 \%$ & 769 & $68.5 \%$ & 474 & $91.0 \%$ & 374 & $38.1 \%$ & 148 & $17.8 \%$ & $<0.001$ \\
\hline Radiotherapy & 724 & $20.9 \%$ & 188 & $16.7 \%$ & 81 & $15.5 \%$ & 206 & $21.0 \%$ & 249 & $30.0 \%$ & $<0.001$ \\
\hline
\end{tabular}

and relevant clinical factors. The frequency of bone sarcoma occurrence was highest in AYA patients, who accounted for a marked proportion of patients with each type of sarcoma. Except for this, no categories were notably more or less prevalent in the AYA patient groups when compared with the same categories in other age groups. The majority of AYA had osteosarcoma 631 (56.2\%), while 198 (17.6\%) had chondrosarcoma. Among children, osteosarcoma was the most common 405 (77.7\%), while 92 (17.7\%) had Ewing sarcoma. Chondrosarcoma was the most common among adults 376 (38.3\%), while 278 (28.3\%) had osteosarcoma. Finally, among elderly, chondrosarcoma was the most common 303 (36.5\%), while 183 (22.0\%) had osteosarcoma. The incidences of osteosarcoma and Ewing sarcoma decreased with age, while the incidences of chondrosarcoma increased with age.
Figure 1a-d shows the cancer survival curves for patients with overall bone sarcoma (all types), as well as in those with osteosarcoma, chondrosarcoma, and Ewing sarcoma. There were no elderly patients with Ewing sarcoma. The cancer survival rate of AYA patients with osteosarcoma tended to be similar to that of children, but was better than those of adult and elderly patients. The cancer survival rate of AYA patients with chondrosarcoma tended to be similar to those of adults and was better than that of elderly patients. The cancer survival rates of children, AYA, and adult patients with Ewing sarcoma exhibited distinct tendencies, while the cancer survival rates of patients with Ewing sarcoma worsened with advancing age.

Table 2 shows the 5 -year cancer survival statistics by age and sarcoma type. AYA patients with overall bone sarcoma did not exhibit worse cancer survival rates; 

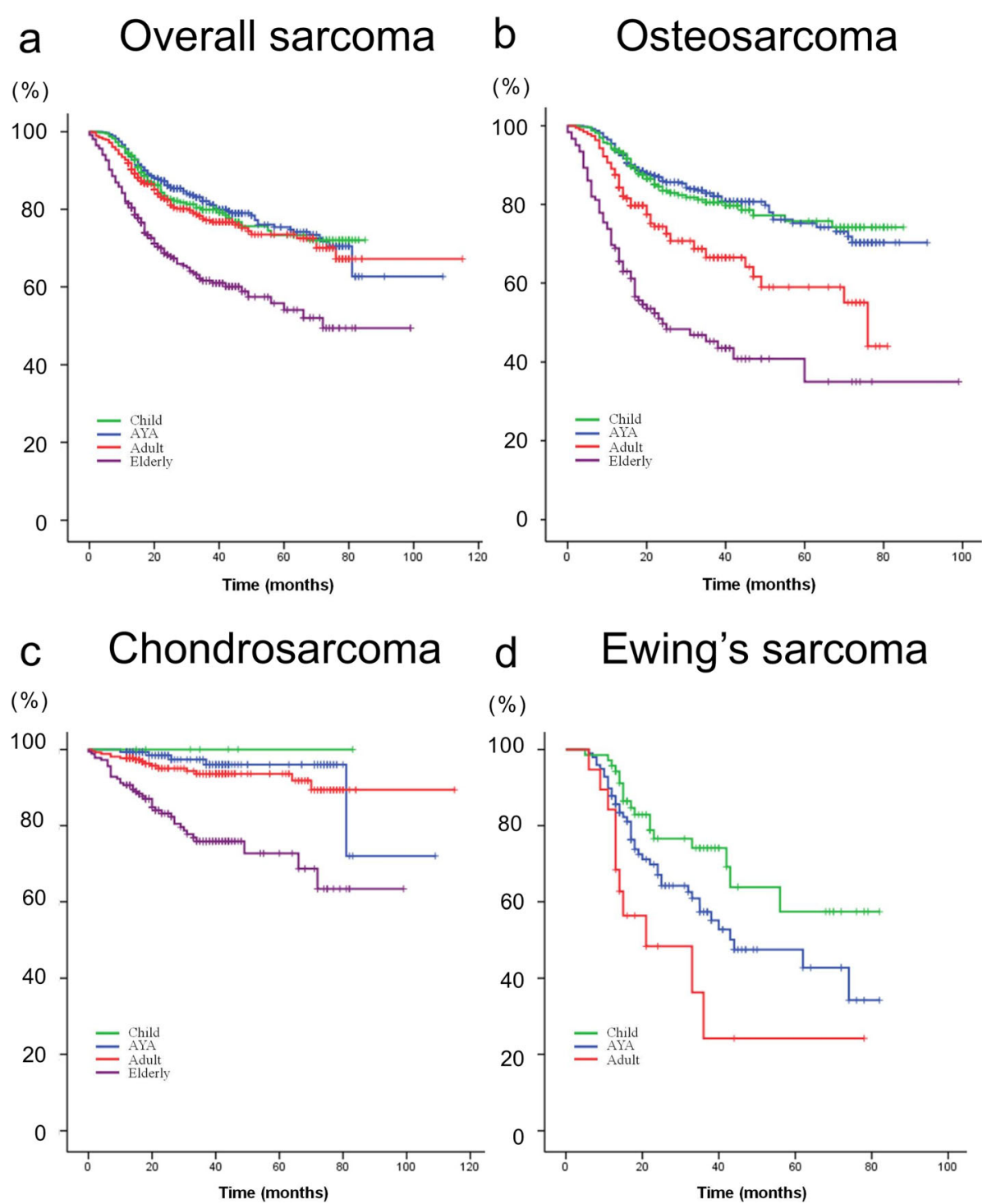

Fig. 1 a-d Kaplan-Meier survival curves showing disease-specific survival for overall sarcoma (a), osteosarcoma (b), chondrosarcoma (c), and Ewing sarcoma (d), stratified by age. Child: $\leq 14$ years, adolescent and young adult (AYA): 15-39 years, adult: 40-64 years, and elderly: $\geq 65$ years. No elderly patients were included in $\mathbf{d}$ as no elderly patients were diagnosed with Ewing sarcoma

Table 2 Five-year survival statistics by age and sarcoma type

\begin{tabular}{|c|c|c|c|c|c|c|c|c|}
\hline \multicolumn{3}{|c|}{ All sarcomas } & \multicolumn{2}{|c|}{ Osteosarcoma } & \multicolumn{2}{|c|}{ Chondrosarcoma } & \multicolumn{2}{|c|}{ Ewing sarcoma } \\
\hline & $\bar{N}$ & 5-year survival (\%) & $\bar{N}$ & 5-year survival (\%) & $\bar{N}$ & 5-year survival (\%) & $\bar{N}$ & 5-year survival (\%) \\
\hline Overall & 2651 & $71.3 \%$ & 1124 & $68.4 \%$ & 603 & $88.0 \%$ & 187 & $49.0 \%$ \\
\hline
\end{tabular}

Age at diagnosis

\begin{tabular}{lllllllll} 
AYA & 912 & $75.3 \%$ & 483 & $75.2 \%$ & 150 & $96.0 \%$ & 98 & $47.5 \%$ \\
Child & 431 & $73.8 \%$ & 327 & $75.7 \%$ & 7 & $100.0 \%$ & 70 & $57.5 \%$ \\
Adult & 741 & $74.2 \%$ & 192 & $59.0 \%$ & 264 & $93.6 \%$ & 19 & $24.2 \%$ \\
Elderly & 567 & $58.5 \%$ & 122 & $35.0 \%$ & 182 & $72.7 \%$ & NA & \\
\hline
\end{tabular}


however, the cancer survival was inversely correlated with age. The same tendencies were observed for each of osteosarcoma, chondrosarcoma, and Ewing sarcoma.

Table 3 shows univariate and multivariate analyses of prognostic factors of cancer survival by sarcoma type.
Overall, the prognostic factors associated with poor cancer survival in patients with overall bone sarcoma were age $\geq 65$ years (hazard ratio [HR]: $3.74 ; 95 \%$ confidence interval $[\mathrm{CI}]: 2.66-5.28 ; P<0.001)$, high tumor grade (HR: 3.77; 95\% CI: 1.93-7.37; $P<0.001$ ), tumor size $>$

Table 3 Univariate and multivariate analyses of prognostic factors of cancer survival by sarcoma type

\begin{tabular}{|c|c|c|c|c|c|c|c|c|}
\hline & \multicolumn{2}{|l|}{ All sarcomas } & \multicolumn{2}{|l|}{ Osteosarcoma } & \multicolumn{2}{|c|}{ Chondrosarcoma } & \multirow{2}{*}{$\begin{array}{l}\text { Ewing } \\
\text { sarcoma } \\
\text { Univariate }\end{array}$} & \multirow[b]{2}{*}{ Multivariate } \\
\hline & Univariate & Multivariate & Univariate & Multivariate & Univariate & Multivariate & & \\
\hline & $\mathrm{HR}(95 \% \mathrm{Cl})$ & $\mathrm{HR}(95 \% \mathrm{Cl})$ & $\mathrm{HR}(95 \% \mathrm{Cl})$ & $\mathrm{HR}(95 \% \mathrm{Cl})$ & $\mathrm{HR}(95 \% \mathrm{Cl})$ & $\mathrm{HR}(95 \% \mathrm{Cl})$ & $\mathrm{HR}(95 \% \mathrm{Cl})$ & $\mathrm{HR}(95 \% \mathrm{Cl})$ \\
\hline \multicolumn{9}{|l|}{ Age at diagnosis } \\
\hline AYA & Reference & Reference & Reference & Reference & Reference & Reference & Reference & Reference \\
\hline Child & $\begin{array}{l}1.04(0.79- \\
1.36)\end{array}$ & $\begin{array}{l}0.83(0.59- \\
1.18)\end{array}$ & $\begin{array}{l}1.02(0.73- \\
1.42)\end{array}$ & $\begin{array}{l}1.00(0.70- \\
1.43)\end{array}$ & & & $\begin{array}{l}0.57(0.33- \\
1.00)\end{array}$ & $\begin{array}{l}0.35(0.15- \\
0.83)\end{array}$ \\
\hline Adult & $\begin{array}{l}1.14(0.92- \\
1.43)\end{array}$ & $\begin{array}{l}1.61(1.16- \\
2.24)\end{array}$ & $\begin{array}{l}1.99(1.42- \\
2.78)\end{array}$ & $\begin{array}{l}1.58(1.11- \\
2.24)\end{array}$ & $\begin{array}{l}1.82(0.66- \\
5.02)\end{array}$ & $\begin{array}{l}1.77(0.63- \\
4.94)\end{array}$ & $\begin{array}{l}1.92(0.98- \\
3.74)\end{array}$ & $\begin{array}{l}1.97(0.69- \\
5.65)\end{array}$ \\
\hline Elderly & $\begin{array}{l}1.99(1.61- \\
2.46)\end{array}$ & $\begin{array}{l}3.74(2.66- \\
5.28)\end{array}$ & $\begin{array}{l}4.35(3.14- \\
6.02)\end{array}$ & $\begin{array}{l}3.26(2.29- \\
4.64)\end{array}$ & $\begin{array}{l}7.38(2.91- \\
18.75)\end{array}$ & $\begin{array}{l}6.13(2.38- \\
15.75)\end{array}$ & NA & NA \\
\hline \multicolumn{9}{|l|}{ Sex } \\
\hline Male & Reference & Reference & Reference & Reference & Reference & Reference & Reference & Reference \\
\hline Female & $\begin{array}{l}0.93(0.79- \\
1.10)\end{array}$ & $\begin{array}{l}0.85(0.68- \\
1.06)\end{array}$ & $\begin{array}{l}1.01(0.80- \\
1.29)\end{array}$ & $\begin{array}{l}0.96(0.75- \\
1.23)\end{array}$ & $\begin{array}{l}1.07(0.64- \\
1.78)\end{array}$ & $\begin{array}{l}1.20(0.70- \\
2.06)\end{array}$ & $\begin{array}{l}0.96(0.60- \\
1.55)\end{array}$ & $\begin{array}{l}1.08(0.53- \\
2.19)\end{array}$ \\
\hline \multicolumn{9}{|l|}{ Histologic grade } \\
\hline Low & Reference & Reference & & & Reference & Reference & & \\
\hline High & $\begin{array}{l}6.63(4.71- \\
9.34)\end{array}$ & $\begin{array}{l}3.77(1.93- \\
7.37)\end{array}$ & & & $\begin{array}{l}4.73(2.75- \\
8.14)\end{array}$ & $\begin{array}{l}3.27(1.84- \\
5.83)\end{array}$ & & \\
\hline \multicolumn{9}{|l|}{ Tumor size } \\
\hline$\leq 8 \mathrm{~cm}$ & Reference & Reference & Reference & Reference & Reference & Reference & Reference & Reference \\
\hline$>8 \mathrm{~cm}$ and $\leq 16 \mathrm{~cm}$ & $\begin{array}{l}1.84(1.53- \\
2.21)\end{array}$ & $\begin{array}{l}1.26(0.99- \\
1.62)\end{array}$ & $\begin{array}{l}1.74(1.32- \\
2.30)\end{array}$ & $\begin{array}{l}1.63(1.23- \\
2.16)\end{array}$ & $\begin{array}{l}2.79(1.55- \\
5.02)\end{array}$ & $\begin{array}{l}2.03(1.12- \\
3.70)\end{array}$ & $\begin{array}{l}0.86(0.51- \\
1.44)\end{array}$ & $\begin{array}{l}0.55(0.25- \\
1.23)\end{array}$ \\
\hline$>16 \mathrm{~cm}$ & $\begin{array}{l}2.92(2.21- \\
3.87)\end{array}$ & $\begin{array}{l}2.20(1.52- \\
3.19)\end{array}$ & $\begin{array}{l}2.65(1.74- \\
4.030)\end{array}$ & $\begin{array}{l}2.84(1.86- \\
4.35)\end{array}$ & $\begin{array}{l}4.81(2.30- \\
10.07)\end{array}$ & $\begin{array}{l}3.06(1.40- \\
6.68)\end{array}$ & $\begin{array}{l}3.00(1.41- \\
6.37)\end{array}$ & $\begin{array}{l}2.39(0.87- \\
6.57)\end{array}$ \\
\hline \multicolumn{9}{|l|}{ Tumor location } \\
\hline Upper extremity & Reference & Reference & Reference & Reference & Reference & Reference & Reference & Reference \\
\hline Lower extremity & $\begin{array}{l}1.64(1.14- \\
2.37)\end{array}$ & $\begin{array}{l}1.41(0.94- \\
2.12)\end{array}$ & $\begin{array}{l}1.30(0.79- \\
2.14)\end{array}$ & $\begin{array}{l}1.19(0.72- \\
1.98)\end{array}$ & $\begin{array}{l}2.65(0.78- \\
9.04)\end{array}$ & $\begin{array}{l}2.30(0.66- \\
8.03)\end{array}$ & $\begin{array}{l}1.37(0.52- \\
3.61)\end{array}$ & $\begin{array}{l}1.63(0.51- \\
5.22)\end{array}$ \\
\hline Trunk & $\begin{array}{l}2.48(1.72- \\
3.59)\end{array}$ & $\begin{array}{l}1.43(0.91- \\
2.23)\end{array}$ & $\begin{array}{l}4.43(2.63- \\
7.46)\end{array}$ & $\begin{array}{l}2.64(1.53- \\
4.56)\end{array}$ & $\begin{array}{l}4.40(1.36- \\
14.25)\end{array}$ & $\begin{array}{l}3.62(1.08- \\
12.15)\end{array}$ & $\begin{array}{l}1.01(0.40- \\
2.55)\end{array}$ & $\begin{array}{l}1.19(0.36- \\
3.91)\end{array}$ \\
\hline Head and neck & $\begin{array}{l}1.93(0.75- \\
4.95)\end{array}$ & $\begin{array}{l}0.82(0.19- \\
3.51)\end{array}$ & $\begin{array}{l}1.35(0.40- \\
4.60)\end{array}$ & $\begin{array}{l}1.73(0.50- \\
6.04)\end{array}$ & & & $\begin{array}{l}1.78(0.21- \\
15.34)\end{array}$ & $\begin{array}{l}5.16(0.53- \\
50.02)\end{array}$ \\
\hline Multiple disease & $\begin{array}{l}5.99(3.68- \\
9.74)\end{array}$ & $\begin{array}{l}2.60(1.17- \\
5.78)\end{array}$ & & & & & & \\
\hline \multicolumn{9}{|l|}{ Limb salvage } \\
\hline Salvaged & Reference & Reference & Reference & Reference & Reference & & Reference & \\
\hline Amputated & $\begin{array}{l}2.15(1.72- \\
2.70)\end{array}$ & $\begin{array}{l}2.98(2.28- \\
3.89)\end{array}$ & $\begin{array}{l}2.47(1.83- \\
3.33)\end{array}$ & $\begin{array}{l}2.80(2.05- \\
3.83)\end{array}$ & $\begin{array}{l}1.56(0.62- \\
3.96)\end{array}$ & & $\begin{array}{l}2.01(0.80- \\
5.07)\end{array}$ & \\
\hline \multicolumn{9}{|l|}{ Surgical margin } \\
\hline $\begin{array}{l}\text { Negative (wide or } \\
\text { marginal) }\end{array}$ & Reference & Reference & Reference & & Reference & & Reference & Reference \\
\hline Positive (intralesional) & $\begin{array}{l}1.14(0.81- \\
1.60)\end{array}$ & $\begin{array}{l}1.78(1.21- \\
2.62)\end{array}$ & $\begin{array}{l}1.26(0.52- \\
3.07)\end{array}$ & & $\begin{array}{l}0.68(0.26- \\
1.76)\end{array}$ & & $\begin{array}{l}3.67(1.60- \\
8.40)\end{array}$ & $\begin{array}{l}5.28(1.90- \\
14.62)\end{array}$ \\
\hline
\end{tabular}


$16 \mathrm{~cm}$ (HR: 2.20; 95\% CI: 1.52-3.19; $P<0.001$ ), and positive surgical margins (HR: 1.78 ; 95\% CI: $1.21-2.62 ; P=$ 0.004) (Table 3).

The results of univariate and multivariate analysis of prognostic factors for cancer survival in patients with osteosarcoma are shown in Table 3. Upon multivariate analysis, the negative prognostic factors included age 40-64 years (HR: 1.58; 95\% CI: $1.11-2.24 ; P<0.001$ ), age $\geq 65$ years (HR: 3.26; 95\% CI: 2.29-4.64; $P<0.001$ ), tumor size > $16 \mathrm{~cm}$ (HR: 2.84; 95\% CI: $1.86-4.35 ; P<$ 0.001), and tumor location on the trunk (HR: 2.64; $95 \%$ CI: $1.53-4.56 ; P<0.001$ ) (Table 3). AYA patients had a similar HR to children and did not exhibit an increased risk of tumor-related death compared with the other age groups.

Likewise, the prognostic factors associated with poor cancer survival in patients with chondrosarcoma were age $\geq 65$ years (HR: 6.13; 95\% CI: $2.38-15.75 ; P<$ 0.001 ), tumor size $>16 \mathrm{~cm}$ (HR: 3.06; 95\% CI: 1.40-6.68; $P=0.005$ ), and tumor location on the trunk (HR: 3.62; 95\% CI: $1.08-12.15 ; P=0.038$ ) (Table 3). Being in the AYA age group did not increase the risk of tumor-related deaths compared with the child and adult groups; furthermore, the risk of tumor-related deaths in AYA patients was lower than that in the elderly group.

Lastly, the sole prognostic factor associated with poor cancer survival in patients with Ewing sarcoma was a positive surgical margin (HR: 5.28; 95\% CI: 1.90-14.62; $P=0.001$ ). AYA patients had an increased risk of tumor-related deaths compared with children (HR: 0.35; 95\% CI: $0.15-0.83 ; P=0.016)$, but not with adults. None of the patients with Ewing sarcoma in our study were $\geq$ 65 years of age (Table 3 ).

\section{Discussion}

There have been fewer improvements in the clinical outcomes of AYA patients with cancer than for children and older adults, possibly because fewer studies focus on patients in this age group. Our study revealed the outcomes of AYA patients with bone sarcomas. We found that the AYA age group was not an independent poor prognostic factor for bone sarcoma overall, or for osteosarcoma, chondrosarcoma, or Ewing sarcoma individually. This was in contrast to other cancers, such as those of the breast and colon [17]. The cancer survival rate in AYA patients with bone sarcoma was similar to that of children and adults, and was more favorable than that of elderly patients. However, there have been no significant improvements in the overall 5-year survival rates for patients with bone sarcoma over the past few decades, unlike other cancers [10]. It is possible that this finding is the same in Japan. There have been significant improvements in the overall 5-year relative survival rates for patients with other cancers because of established effective chemotherapy and molecular targeted drugs $[18,19]$. It is possible that AYA patients do not stand out because there have been no improvements in the overall 5-year relative survival rates for other age groups.

In addition, insurance rates are significantly lower in AYA patients [20]. AYA cancer survivors without health insurance do not receive cancer-related medical care, while those with insurance do [21]. In Japan, every Japanese person belongs to the public medical insurance that bears $70-90 \%$ of the treatment costs. Japan has a national bail out system for officially acknowledged people in need, which covers almost $100 \%$ of the actual treatment costs. It is possible that cancer survival rates of AYA patients did not differ from patients in other age groups because patients of all ages received equal medical treatment. To our knowledge, this study is the first to investigate bone sarcomas based on age groups, including AYAs, and their clinical outcomes [22, 23].

Previous epidemiological analyses conducted in Australia and the United States showed that the cancer survival rates of AYA patients with osteosarcoma were significantly worse than those of children $[10,11]$. However, our study showed that Japanese AYA patients with osteosarcoma had cancer survival rates that were statistically equivalent to those in children. The standard chemotherapy for osteosarcoma is methotrexate, doxorubicin, and cisplatin (MAP). Although the use of chemotherapy children and AYA patients was high, it was infrequently used in adult patients (data not shown). This likely explains why the cancer survival rates of AYA patients with osteosarcoma were better than those in adult and elderly patients. One other possible reason is that in Japan, one of the inclusion criteria for many clinical trials regarding osteosarcoma is patients aged $\leq 40$ years [24-26]. AYA patients with osteosarcoma receive the same therapy as children. Tumor size is one of prognostic factors associated with poor survival among those with osteosarcoma [27]. In this study, there were few differences in the mean tumor size between AYA and adult patients (Additional file 1). Although children had the best osteosarcoma outcomes, the mean tumor size in children was the largest. For chondrosarcoma in particular, we found no other published studies with which to compare our results. The cancer survival rates of elderly patients with chondrosarcoma in our study were inferior to those of other age groups. One possible reason for this might be that elderly patients cannot be treated using surgery as a result of their advanced age. The proportions of patients who underwent surgery in the various age groups were as follows: children, $85.7 \%$; AYA, 86.0\%; adults, $87.1 \%$; elderly, $73.1 \%$ (data not shown).

Tumor size is also a prognostic factor in Ewing sarcoma [28]. In this study, there were no significant differences in the mean tumor size between the age groups. 
One possible reason for this might be the distinct biological features of Ewing sarcoma in different age groups. It was reported that a gain in chromosome 1q and a loss in chromosome 16q were each associated with significantly worse outcomes; these mutations were more common in patients' $\geq 15$ years of age than in children [29]. Hence, the biology of Ewing sarcoma in AYA patients appears to be distinct from that in children [29]. In our study the frequency of Ewing sarcoma in AYA patients in Japan was lower than that in Australia and the United States [9, 11]. This is the reason why Caucasian populations are much more frequently affected, while there are low rates of the disease in East Asian and African populations [30].

The other independent risk factors for poor cancer survival in patients with bone sarcoma, as revealed in our study, are similar to those in previous studies of similar types of sarcoma. Consistent with our study, previous studies also reported that older age, large tumor size, high grade, and positive surgical margins were major factors that adversely influenced prognoses [28, 31-33].

Our study had several limitations. First, the BSTT Registry was computerized in 2006, and no long-term observations of over 10-years were possible. Second, there were many patients for whom functional outcomes were not recorded in the BSTT Registry; these would have been useful to evaluate. Third, AYA cancer survivors experience adverse effects on their quality of life that persist beyond cancer diagnosis and treatment, including issues with infertility, body image, difficulty establishing relationships, and many other aspects of physical and social functioning [18]. There are no data with which to evaluate such parameters in the BSTT Registry. Forth, due to the extremely low incidence rate, the number of children with chondrosarcoma and elderly with Ewing sarcoma was insufficient. However, despite these limitations, our findings provide detailed information on the epidemiology of bone sarcoma among AYAs in Japan.

\section{Conclusions}

Our study is the first to provide data on the descriptive epidemiology and clinical outcomes of AYA patients with bone sarcomas using a nationwide, large-scale database. We found that, contrary to expectations, cancer survival rates of AYA patients with bone sarcomas were not inferior to those of other age groups in Japan.

\section{Additional file}

Additional file 1: Tumor size by age and sarcoma type. (DOCX 23 kb)

\section{Abbreviations}

AYA: Adolescent and young adult; BSTT: Bone and soft tissue tumor (registry); Cl: Confidence interval; HR: Hazard ratio

\section{Acknowledgments}

We would like to thank all the subjects who volunteered for this study.

\section{Availability of data and materials}

The datasets generated during and/or analysed during the current study are not publicly available due to anonymized patient data by the Japanese Orthopaedic Association. Data are however available from the authors upon reasonable request and with permission of the Japanese Orthopaedic Association.

\section{Authors' contributions}

$T F, K O, T A$ and $A K$ contributed to the conception and design of the study. $\mathrm{TF}, \mathrm{KO}, \mathrm{TA}$ and $\mathrm{KT}$ contributed to the analysis, and all authors contributed to the interpretation of the results. TF drafted the article; all authors revised it critically and approved the final version submitted for publication. All authors read and approved the final manuscript.

\section{Ethics approval and consent to participate}

The research has been approved by the Ethic Committee of the Japanese Orthopaedic Association on March 17, 2016. This was a retrospective study carried out using data from the Bone and Soft Tissue Tumor registry; the authors were not involved in the collection of this data. Patients were informed that their data would be used for research and their data were deidentified before addition to the database. Retrieval of the data from this database occurred in an unlinked fashion. As the data had been anonymized, the Ethical Guidelines for Epidemiological Research (Ministry of Education, Culture, Sports, Science and Technology, and Ministry of Health, Labour and Welfare of Japan), which require ethics approval and informed consent, are not applicable to this study. Based on the Ethical Guidelines on Biomedical Research Involving Human Subjects (Ministry of Education, Culture, Sports, Science and Technology, and Ministry of Health, Labour and Welfare of Japan), clinicoepidemiological studies conducted on medical databases constitute research carried out on pre-existing material and information, that did not require any interventions or interactions with patients. For such studies, including this study, obtaining written informed consent from patients is not compulsory.

\section{Consent for publication}

Not Applicable.

\section{Competing interests}

The authors declare that they have no competing interests.

\section{Publisher's Note}

Springer Nature remains neutral with regard to jurisdictional claims in published maps and institutional affiliations.

\section{Author details}

'Department of Orthopaedic Surgery, Saitama Medical Center, Jichi Medical University, Saitama, Japan. ${ }^{2}$ Department of Orthopaedic Surgery, Jichi Medical University, Tochigi, Japan. ${ }^{3}$ Department of Musculoskeletal Oncology, National Cancer Center Hospital, Tokyo, Japan. ${ }^{4}$ Department of Orthopaedic Surgery, Faculty of Medicine, The University of Tokyo, Tokyo, Japan.

Received: 9 January 2018 Accepted: 1 August 2018

Published online: 18 August 2018

\section{References}

1. Potosky AL, Harlan LC, Albritton K, Cress RD, Friedman DL, Hamilton AS, et al. Use of appropriate initial treatment among adolescents and young adults with cancer. J Natl Cancer Inst. 2014;106(11). https://doi.org/10.1093/ jnci/dju300. Print 2014 Nov.

2. Albritton $\mathrm{K}$, Bleyer WA. The management of cancer in the older adolescent. Eur J Cancer. 2003;39(18):2584-99.

3. Bleyer A, Budd T, Montello M. Adolescents and young adults with cancer: the scope of the problem and criticality of clinical trials. Cancer. 2006;107(7 Suppl):1645-55.

4. Thomas DM, Albritton KH, Ferrari A. Adolescent and young adult oncology: an emerging field. J Clin Oncol. 2010;28(32):4781-2.

5. Children's Oncology Group, SEER Program (National Cancer Institute (U.S.)). Cancer epidemiology in older adolescents and young adults 15 to 29 years 
of age : including SEER incidence and survival, 1975-2000. Bethesda: U.S Dept. of Health and Human Services, National Institutes of Health, National Cancer Institute; 2006. x, 205 p. p.

6. Stiller CA, Trama A, Serraino D, Rossi S, Navarro C, Chirlaque MD, et al. Descriptive epidemiology of sarcomas in Europe: report from the RARECARE project. Eur J Cancer. 2013:49(3):684-95.

7. Eleuterio SJ, Senerchia AA, Almeida MT, Da Costa CM, Lustosa D, Calheiros LM, et al. Osteosarcoma in patients younger than 12 years old without metastases have similar prognosis as adolescent and young adults. Pediatr Blood Cancer. 2015;62(7):1209-13.

8. Haggar FA, Preen DB, Pereira G, Holman CD, Einarsdottir K. Cancer incidence and mortality trends in Australian adolescents and young adults 1982-2007. BMC Cancer. 2012;12:151.

9. Herzog CE. Overview of sarcomas in the adolescent and young adult population. J Pediatr Hematol Oncol. 2005;27(4):215-8.

10. Keegan TH, Ries LA, Barr RD, Geiger AM, Dahlke DV, Pollock BH, et al. Comparison of cancer survival trends in the United States of adolescents and young adults with those in children and older adults. Cancer. 2016; 122(7):1009-16.

11. Khamly KK, Thursfield VJ, Fay M, Desai J, Toner GC, Choong PF, et al. Genderspecific activity of chemotherapy correlates with outcomes in chemosensitive cancers of young adulthood. Int J Cancer. 2009;125(2):426-31.

12. Ogura K, Higashi T, Kawai A. Statistics of bone sarcoma in Japan: report from the bone and soft tissue tumor registry in Japan. J Orthop Sci. 2017; 22(1):133-43.

13. Balamuth NJ, Womer RB. Ewing's sarcoma. Lancet Oncol. 2010;11(2):184-92.

14. Grier HE, Krailo MD, Tarbell NJ, Link MP, Fryer CJ, Pritchard DJ, et al. Addition of ifosfamide and etoposide to standard chemotherapy for Ewing's sarcoma and primitive neuroectodermal tumor of bone. N Engl J Med. 2003;348(8): 694-701.

15. Bielack SS, Kempf-Bielack B, Delling G, Exner GU, Flege S, Helmke K, et al. Prognostic factors in high-grade osteosarcoma of the extremities or trunk: an analysis of 1,702 patients treated on neoadjuvant cooperative osteosarcoma study group protocols. J Clin Oncol. 2002;20(3):776-90.

16. Giuffrida AY, Burgueno JE, Koniaris LG, Gutierrez JC, Duncan R, Scully SP. Chondrosarcoma in the United States (1973 to 2003): an analysis of 2890 cases from the SEER database. J Bone Joint Surg Am. 2009;91(5):1063-72.

17. Tricoli JV, Seibel NL, Blair DG, Albritton K, Hayes-Lattin B. Unique characteristics of adolescent and young adult acute lymphoblastic leukemia, breast cancer, and colon cancer. J Natl Cancer Inst. 2011;103(8):628-35.

18. Pfreundschuh $M$, Trumper $L$, Osterborg A, Pettengell $R$, Trneny $M$, Imrie $K$, et al. CHOP-like chemotherapy plus rituximab versus CHOP-like chemotherapy alone in young patients with good-prognosis diffuse large-B-cell lymphoma: a randomised controlled trial by the MabThera international trial (MInT) group. Lancet Oncol. 2006;7(5):379-91.

19. Roy L, Guilhot J, Krahnke T, Guerci-Bresler A, Druker BJ, Larson RA, et al. Survival advantage from imatinib compared with the combination interferon-alpha plus cytarabine in chronic-phase chronic myelogenous leukemia: historical comparison between two phase 3 trials. Blood. 2006; 108(5):1478-84.

20. Adams SH, Newacheck PW, Park MJ, Brindis CD, Irwin CE Jr. Health insurance across vulnerable ages: patterns and disparities from adolescence to the early 30s. Pediatrics. 2007;119(5):e1033-9.

21. Keegan TH, Tao L, DeRouen MC, Wu XC, Prasad P, Lynch CF, et al. Medical care in adolescents and young adult cancer survivors: what are the biggest access-related barriers? J Cancer Surviv. 2014;8(2):282-92.

22. Akiyama T, Saita K, Chikuda H, Horiguchi H, Fushimi K, Yasunaga $H$. Mortality and morbidity following surgery for primary malignant musculoskeletal tumors in the pelvis and limbs: a retrospective analysis using the Japanese diagnosis procedure combination database. J Cancer Ther. 2016;07(04):303-10.

23. Ogura $K$, Yasunaga H, Horiguchi H, Ohe K, Shinoda Y, Tanaka S, et al. Impact of hospital volume on postoperative complications and in-hospital mortality after musculoskeletal tumor surgery: analysis of a national administrative database. J Bone Joint Surg Am. 2013;95(18):1684-91.

24. Ferrari S, Ruggieri P, Cefalo G, Tamburini A, Capanna R, Fagioli F, et al. Neoadjuvant chemotherapy with methotrexate, cisplatin, and doxorubicin with or without ifosfamide in nonmetastatic osteosarcoma of the extremity: an Italian sarcoma group trial ISG/OS-1. J Clin Oncol. 2012;30(17):2112-8.

25. Kudawara I, Aoki Y, Ueda T, Araki N, Naka N, Nakanishi H, et al. Neoadjuvant and adjuvant chemotherapy with high-dose ifosfamide, doxorubicin, cisplatin and high-dose methotrexate in non-metastatic osteosarcoma of the extremities: a phase II trial in Japan. J Chemother. 2013:25(1):41-8.

26. Whelan JS, Bielack SS, Marina N, Smeland S, Jovic G, Hook JM, et al. EURAMOS-1, an international randomised study for osteosarcoma: results from pre-randomisation treatment. Ann Oncol. 2015;26(2):407-14.

27. Bieling $P$, Rehan $N$, Winkler $P$, Helmke $K$, Maas R, Fuchs $N$, et al. Tumor size and prognosis in aggressively treated osteosarcoma. J Clin Oncol. 1996; 14(3):848-58.

28. Duchman KR, Gao Y, Miller BJ. Prognostic factors for survival in patients with Ewing's sarcoma using the surveillance, epidemiology, and end results (SEER) program database. Cancer Epidemiol. 2015;39(2):189-95.

29. Bleyer A, Barr R, Hayes-Lattin B, Thomas D, Ellis C, Anderson B, et al. The distinctive biology of cancer in adolescents and young adults. Nat Rev Cancer. 2008;8(4):288-98

30. Worch J, Matthay KK, Neuhaus J, Goldsby R, DuBois SG. Ethnic and racial differences in patients with Ewing sarcoma. Cancer. 2010;116(4):983-8.

31. Bertrand TE, Cruz A, Binitie O, Cheong D, Letson GD. Do surgical margins affect local recurrence and survival in extremity, nonmetastatic, high-grade osteosarcoma? Clin Orthop Relat Res. 2016;474(3):677-83.

32. Buchner $M$, Bernd $L$, Zahlten-Hinguranage A, Sabo D. Primary malignant tumours of bone and soft tissue in the elderly. Eur J Surg Oncol. 2004; 30(8):877-83.

33. Duchman KR, Gao Y, Miller BJ. Prognostic factors for survival in patients with high-grade osteosarcoma using the surveillance, epidemiology, and end results (SEER) program database. Cancer Epidemiol. 2015;39(4):593-9.

\section{Ready to submit your research? Choose BMC and benefit from:}

- fast, convenient online submission

- thorough peer review by experienced researchers in your field

- rapid publication on acceptance

- support for research data, including large and complex data types

- gold Open Access which fosters wider collaboration and increased citations

- maximum visibility for your research: over $100 \mathrm{M}$ website views per year

At $\mathrm{BMC}$, research is always in progress.

Learn more biomedcentral.com/submissions 